\title{
Cooling cows with sprinklers: Spray duration affects physiological responses to heat load
}

\author{
Grazyne Tresoldi, ${ }^{*}$ Karin E. Schütz, $†$ and Cassandra B. Tucker**1 \\ ${ }^{*}$ Center for Animal Welfare, Department of Animal Science, University of California, Davis 95616 \\ †AgResearch Ltd., Hamilton 3240, New Zealand
}

\begin{abstract}
Sprayed water reduces heat load in cattle. Determining appropriate spraying strategies (i.e., time on and off) may improve cooling efficiency and reduce water use. Our objective was to evaluate the effects of a single spray on the surrounding air temperature (AT), time it takes the coat to dry, and physiological responses to heat load in dairy cows. In a crossover design, spray duration $(0,0.5,1.5,3$, and $13 \mathrm{~min}$; flow rate: $4.9 \mathrm{~L} /$ min) was tested in 15 Holstein cows (milk yield: 37.7 $\pm 2.6 \mathrm{~kg} / \mathrm{d}$ ) restrained in shaded head gates at the feed bunk for up to $1.75 \mathrm{~h}$. Each treatment was replicated on $3 \mathrm{~d}$ ( $15 \mathrm{~d}$ total/cow) when AT, humidity, and temperature-humidity index averaged $31 \pm 3^{\circ} \mathrm{C}, 27 \pm$ $10 \%$, and $76 \pm 2$, respectively (mean $\pm \mathrm{SD}$ ). Water temperature at the nozzle outlet and dripping from the cow was measured every $1 \mathrm{~s}$ and averaged (mean \pm SD) $29.7 \pm 1.4$ and $30.3 \pm 0.8^{\circ} \mathrm{C}$, respectively. Respiration rate, skin temperature of the shoulder and upper leg, and the surrounding AT were measured before and after the spray application and every $3 \mathrm{~min}$ for $30 \mathrm{~min}$. At the same intervals, using water-sensitive paper we measured the time the coat took to dry. In contrast to the control, immediately after the spray was turned off, all water treatments reduced skin temperature on the shoulder (range of mean $\pm \mathrm{SE}:-1.1$ to $-4.4 \pm 0.2^{\circ} \mathrm{C}$ ). Within the same period, treatments $\geq 1.5$ min reduced respiration rate (range: -7 to $-24 \pm 2$ breaths/min) and the surrounding AT (range: -0.3 to $-1.7 \pm 0.0^{\circ} \mathrm{C}$ ). Only spraying cows for $\geq 3$ min reduced leg surface temperature during spray duration (range of reduction: -0.1 to $-0.6 \pm 0.0^{\circ} \mathrm{C}$ ). Spray duration had little effect on the time it took the coat to dry. Cows sprayed for 13 min took 2 min longer to dry compared with the other treatments (15.9 vs. $13.8,14.9$, and $14.2 \pm 0.6 \mathrm{~min}$, respectively, for $0.5,1.5$, and $3 \mathrm{~min}$ ). No additional cool-
\end{abstract}

Received September 8, 2017.

Accepted January 20, 2018.

${ }^{1}$ Corresponding author: cbtucker@ucdavis.edu ing was observed in this phase except on windier days, when leg temperature and respiration rate reductions tended to be more marked (slope estimates: -0.06 and -3.6 , respectively). Cooling benefits, as well as changes in AT surrounding the leg, were more pronounced when water was sprayed for longer. In this study, cooling was observed primarily when water was turned on, not during the time it took the coat to dry.

Key words: heat loss, evaporation, soaker, water temperature

\section{INTRODUCTION}

Compared with shade alone, sprayed water is an effective strategy to reduce heat load in cattle (Kendall et al., 2007; Chen et al., 2013, 2016a). However, changes in weather patterns, including drought periods, have raised concerns about using potable water in agriculture, requiring more efficient use of this resource (World Resources Institute, 2011). In California, for example, it was estimated that a 1,000-cow dairy farm uses between 2,300 and 25,600 L of water hourly to cool lactating cows in their home pen during the summer (Tresoldi et al., 2017). Although the upper range of water use may relieve heat load and enhance welfare and production, other studies have found that using more water does not necessarily result in more cooling (Means et al., 1992; Chen et al., 2016a).

Dairy cows are usually sprayed at the milking parlor (waiting or holding area) and in their home pen by nozzles located over the feed line or directed toward resting areas (Valtorta and Gallardo, 2004; Anderson et al., 2013; Tresoldi et al., 2017). The quantity of water used can be manipulated in several ways, including via flow rate, spray type (e.g., misters vs. soakers), the temperature threshold at which the spray is activated, and the timing of when the water cycles (i.e., time on and off or, respectively, spray duration and time to dry; Tresoldi et al., 2017). The effects of these manipulations on cow cooling are variable. For example, the rate at which water is applied has been shown to affect cooling but only to a certain extent; no differences in 
heat load were found when comparing flow rates $\geq 1.3$ L/min (Means et al., 1992; Chen et al., 2015, 2016a). In contrast, manipulating the time when the spray is activated (usually controlled by air temperature; $\mathbf{A T}$ ) can affect water use and responses to heat load in cattle. For example, Morrison et al. (1981) found that using higher AT thresholds (i.e., less water; 32 vs. $22^{\circ} \mathrm{C}$ ) resulted in lower feed intake in beef cattle.

The effects of spray timing on cow cooling are poorly understood. The time the water is on and off varies across studies, ranging from $10 \mathrm{~s}$ to $6 \mathrm{~min}$ and from 3.5 to $14 \mathrm{~min}$, respectively (Flamenbaum et al., 1986; Brouk et al., 2003; Tresoldi et al., 2017). Others have found that cows exhibited lower respiration rates and body temperature when wetting frequency was shorter (every 5 vs. 10 or 15 min for every 1 min of spray/cycle; Brouk et al., 2003) and coat wetting was longer (20 or 30 vs. 10 s of spray every 4.5 min; Flamenbaum et al., 1986) than when more time elapsed between spray or when water was sprayed for less time. However, more research is needed to understand how timing affects cow cooling to optimize water use.

Sprinklers are thought to reduce heat load in cattle mainly via evaporation when water is turned off and via fluid and air convection on skin and coat surfaces (Kimmel et al., 1991; Hillmann et al., 2001; Gebremedhin and $\mathrm{Wu}, 2002)$. Some researchers have also speculated that the small droplets of water could reduce the temperature of the air cows inhale, enhancing cooling (Bucklin et al., 1991). To our knowledge, no studies have systematically examined how sprayed water affects the time it takes the coat to dry or the effects of the latter on physiological responses to heat load in cattle. In addition, little is known about how the duration of spray affects cooling in cattle. Thus, the objective of this study was to estimate how the duration of spray affects the time it takes for the coat to dry and physiological responses to heat load in dairy cattle up to $30 \mathrm{~min}$ after the end of the spray application. We hypothesized that cooling would occur during both spray application and the drying time that follows. We also hypothesized that the duration of spray would have little effect on the time it takes the coat to dry but would be positively related to reduction of heat load in cattle in a linear fashion.

\section{MATERIALS AND METHODS}

\section{Animals and Housing}

This study was carried out in August 2015 at the University of California, Davis Dairy Teaching and
Research Facility, and all procedures were approved by the University of California, Davis Institutional Animal Care and Use Committee. Fifteen lactating Holstein cows with average milk yield $37.7 \pm 2.6 \mathrm{~kg} / \mathrm{d}$, DIM 243 \pm 85 , and parity $1.5 \pm 0.8$ lactations were used. All cows were housed in the same area as a single herd between the evening $(1900 \mathrm{~h})$ and morning $(0700 \mathrm{~h})$ milkings. During the daytime, however, cows were split into 3 groups of 5 cows each, balanced for milk production. The daytime group pens were made using removable fencing panels (Power River, Provo, UT) and plywood (at the feed bunk area; $2.4 \mathrm{~m}$ high $\times 3.7 \mathrm{~m}$ long). Cows had access to a water trough, shaded feed bunk with a solid roof, and sand-bedded freestalls. Cows were fed a TMR ad libitum twice daily. Cooling was provided through 2 fans positioned above the stalls and sprayed water at the feed bunk line (TF-VP7.5 Turbo FloodJet wide-angle flat-spray tip, $4.9 \mathrm{~L} / \mathrm{min}$; Spraying Systems Co., Wheaton, IL).

\section{Experimental Design}

Cows were tested $35 \mathrm{~m}$ away from the home pen in 5 individual testing pens measuring 3.7 by $2.4 \mathrm{~m}$ (length $\times$ width). These pens were built using fencing panels as described above and were enclosed with plywood on the sides to minimize water drift. Two white canopy tents (north-south orientation; total length $\times$ width: $18 \times 6 \mathrm{~m}$, polyethylene $180 \mathrm{~g} / \mathrm{m}^{2}$; Delta Canopy, McKinney, TX) were used side by side to shade the testing area. Cows were restrained using head gates, and fresh water and feed (TMR topped with grain and alfalfa hay) were provided. In each testing pen, spray water was mounted at the center of the pen, $2 \mathrm{~m}$ above the floor. To generate a flow rate of $4.9 \mathrm{~L}$ of water $/ \mathrm{min}$, the spray apparatus consisted of a nozzle (same model as described above) and a $207-\mathrm{kPa}$ water pressure regulator (PR55-30; Hendrickson Bros., Corona, CA). The water pipe connecting the main water source and the spray nozzles was partially exposed to direct sunlight throughout the day.

The 5 treatments varied in terms of spray duration: (1) $0 \mathrm{~s}$, where no spray was applied (shade only); (2) $0.5 \mathrm{~min}$, which we found to be sufficient to soak the coat from shoulder to hip as determined in a pilot study using 6 cows; (3) $1.5 \mathrm{~min}$; (4) $3 \mathrm{~min}$; and (5) $13 \mathrm{~min}$, which we estimated as the minimum duration necessary for the skin to reach a temperature similar to the water sprayed. This was based on our group's previous results showing that when sprayed water temperature averaged $30.4^{\circ} \mathrm{C}$, shoulder temperature was reduced from about 38.5 to $36.5^{\circ} \mathrm{C}$ after $3 \mathrm{~min}$ of water application (Chen 
et al., 2015). This timing was therefore extrapolated to $13 \mathrm{~min}$ to try to reach $30.4^{\circ} \mathrm{C}$. For each treatment, water was applied once and the nozzles were manually turned on and off.

To capture a range of weather conditions, the daytime groups of cows were tested during one of the following testing periods: 1115 to 1230,1300 to 1445 , or 1515 to $1600 \mathrm{~h}$. Each cow was always tested at the same time. Cows were moved to the testing pens 30 min before the first cow was tested and remained there until data collection was completed (up to $1.75 \mathrm{~h}$ ). All 5 treatments were applied daily in each group. Cows received each treatment 3 times ("replicates"), resulting in $15 \mathrm{~d}$ of data collection. The order in which each cow received each treatment in each replicate was balanced. The treatments were randomly chosen without replacement using unique permutations. In the home pen, sprinklers were turned off $30 \mathrm{~min}$ before moving cows to the testing area to ensure that their coats were dry.

\section{Physiological Measures}

Respiration rate (RR) was measured as time for 10 flank movements and converted to breaths per minute to facilitate comparisons with other studies. These measures were recorded before spray application (-1 min) and every 3 min starting as soon as the spray was turned off for a 30-min period $(0,3,6,9, \ldots, 27,30$ min). Data were collected by 14 observers. Interobserver reliability was calculated using regression analysis $\left(\mathrm{R}^{2}\right.$ $\geq 0.92, P<0.001$; intercept: -0.36 to $0.68, P \geq 0.05$; slope: 0.96 to $1.04, P \geq 0.05$ ).

Skin temperature was measured in 2 locations: $5 \mathrm{~cm}$ behind the caudal angle of the scapula (referred to as the shoulder), and in the medial inner face of the ulna and radius, $12 \mathrm{~cm}$ below the axilla (referred to as the upper leg). The coat was shaved $(10 \times 10 \mathrm{~cm}$ patches $)$, and temperature loggers (Thermochron iButton DS1921HF5, accuracy: $\pm 1.0^{\circ} \mathrm{C}$, resolution: $\pm 0.125^{\circ} \mathrm{C}$; Embedded Data Systems, Lawrenceburg, KY) were placed inside a clear $5 \times 5 \mathrm{~cm}$ reclosable bag and then attached to the skin using 1 layer of white surgical tape $(7.6 \mathrm{~cm}$ wide; 3M Micropore, St. Paul, MN). Another data logger was attached to the caudal face of the ulna (on the upper leg) using a styrofoam "L" shape $(8 \times 12 \mathrm{~cm}$ long, $2 \mathrm{~cm}$ wide) to measure the AT surrounding this area. Data were recorded every $1 \mathrm{~min}$ (from min -1 before spray application to $30 \mathrm{~min}$ after the treatment application). This approach allowed us to use the same device to measure both air and skin temperature, thus avoiding problems in our interpretation associated with differences in device accuracy and precision.

\section{Coat and Logger Moisture}

Cobalt chloride-embedded paper $(2.5 \times 5 \mathrm{~cm}$; Indigo Instruments, Waterloo, ON, Canada) was used to measure changes in coat moisture to estimate the time it took the coat to dry. The paper was briefly pressed against the coat at the shoulder near the data logger and on the flank $5 \mathrm{~cm}$ below the iliac crest. If any pigmentation was observed, the location was recorded as wet (interobserver reliability: $\kappa \geq 0.93$ ). This same technique was used near the upper leg and the nearby data logger to ensure they were dry. If moisture was found in these locations, data from these points were excluded.

\section{Water Measures}

Sprayed water temperature was measured every $1 \mathrm{~s}$ at the nozzle outlet using a thermocouple probe (TJC36-CPSS-062G-6-SMP-M) housed in a ceramic insulator (ORX-116316-6), attached to a temperature data logger (OM-CP-TC101A; accuracy: $\pm 0.5^{\circ} \mathrm{C}$; resolution: $\left.\pm 0.1^{\circ} \mathrm{C}\right)$ stored in a waterproof case (OM-CPWaterbox101A; all products Omega Engineering Inc., Stamford, CT).

The temperature of the water dripping from the cows' left side was measured using a modified plastic funnel (30 cm diameter; More Flavor, Pittsburg, CA) kept 3 $\mathrm{cm}$ away from the body (Figure 1). The funnel was externally covered by a self-adhesive foil and foam layer (duct insulation, Thermwell Products Co., Mahwah, NJ) and sealed with tape to minimize heat exchange with the surroundings. The same thermocouple probe as described above was placed inside the funnel into the stem and recorded the temperature every $1 \mathrm{~s}$. Because thermocouples are more consistent when submerged in water, a piece of polyvinyl chloride pipe and round plastic cap were attached to the end of the stem, where a hole was drilled to drain the water such that the tip of the thermocouple was always immersed (adapted stem length: $18 \mathrm{~cm}$; outlet diameter: $2.5 \mathrm{~cm}$; water outlet diameter: $1 \mathrm{~cm}$ ).

\section{Weather Measures}

A portable weather station (WS-16; Novalynx Corp., Auburn, CA) was placed in an open space approximately $50 \mathrm{~m}$ away from the testing area. Information regarding AT $\left({ }^{\circ} \mathrm{C}\right)$ and black globe temperature (BGT; ${ }^{\circ} \mathrm{C}$ ), wind speed (WS; $\mathrm{m} / \mathrm{s}$ ), relative humidity ( $\mathbf{R H}$; $\%)$, solar radiation $\left(\mathrm{W} / \mathrm{m}^{2}\right)$, and precipitation $(\mathrm{mm})$ was recorded every $5 \mathrm{~min}$. We also estimated temperature-humidity index (THI) and heat load index (HLI) 
using the following equations from Kelly and Bond (1971) and Gaughan et al. (2008), respectively:

$$
\begin{gathered}
\mathrm{THI}=(1.8 \times \mathrm{AT}+32)-[(0.55-0.0055 \times \mathrm{RH}) \\
\times(1.8 \times \mathrm{AT}-26)] \\
\mathrm{HLI}=\text { if } \mathrm{BGT}>25,[8.62+(0.38 \times \mathrm{RH}) \\
+(1.55 \times \mathrm{BGT})+\exp (-\mathrm{WS}+2.4)-0.5 \times \mathrm{WS}], \\
\text { else }[10.66+(0.28 \times \mathrm{RH})+(1.3 \times \mathrm{BGT})-\mathrm{WS}] .
\end{gathered}
$$

\section{Data Management and Statistical Analysis}

All statistical procedures were carried out using SAS (SAS Institute, 2009). The treatment effects on the physiological and surrounding AT measurements were tested using mean values for each cow $(n=15)$ per treatment, comparing the difference between the respective time point $(\min 0,3,9, \ldots, 27$, and 30$)$ and

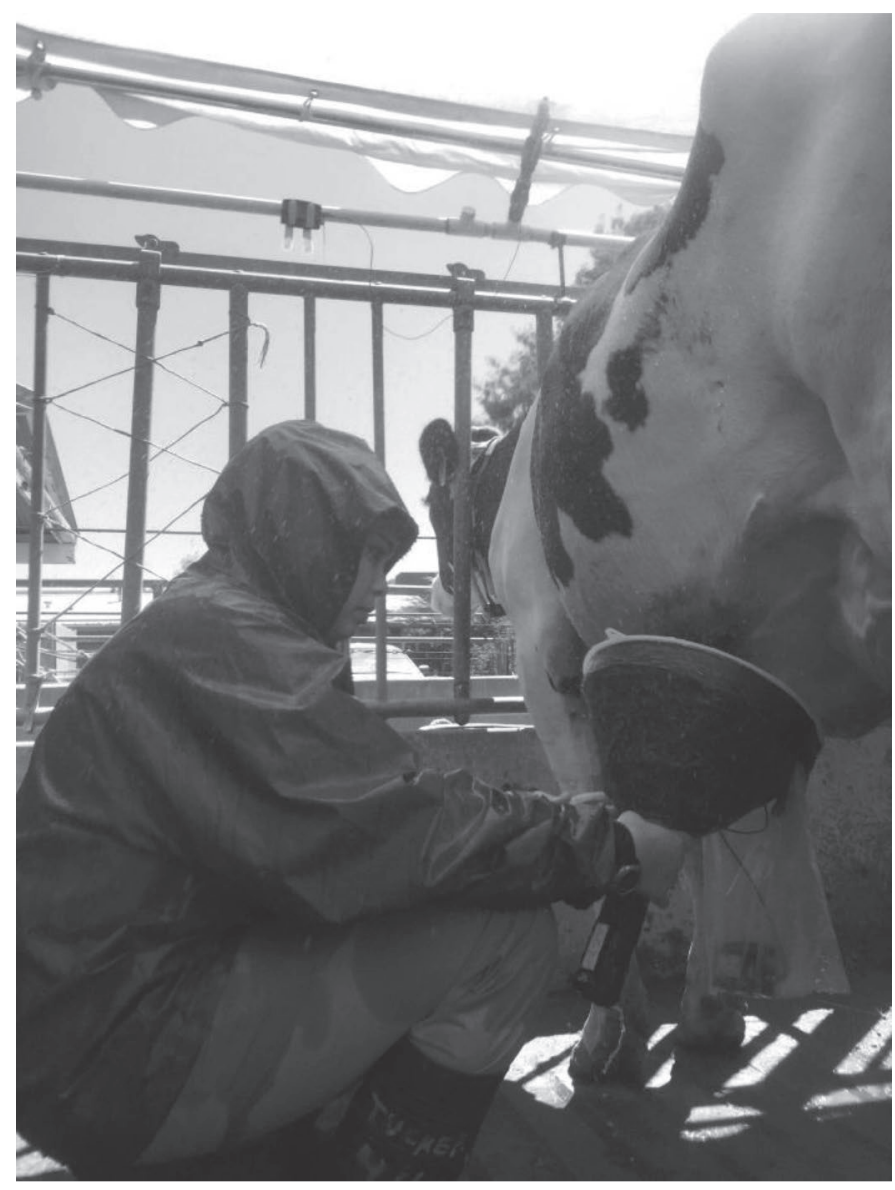

Figure 1. Dripping water collection during spray application. The thermocouple was placed inside the adapted and foam-insulated funnel (30 $\mathrm{cm}$ diameter). baseline values $(\min -1)$. The treatment effects for all the dependent variables were evaluated using mixed models (PROC MIXED). Each model used variance components as the covariance structure, with fixed effect for treatment and random effects for cow. Degrees of freedom were estimated using containment method (treatment $\mathrm{df}=4$, error $\mathrm{df}=56$ ). Pairwise comparisons were done using the PDIFF command. Similar models were used to test the effects of treatment (test $\mathrm{df}=$ 3 , error $\mathrm{df}=42$ ) on time taken to dry [except for the covariance structure used: heterogeneous $\mathrm{AR}(1)]$, water temperature at the nozzle, and dripping from the cow. For dripping water temperature, values from the first $20 \mathrm{~s}$ were excluded because of the time it took for water to begin to drip.

To test for the effects of AT, THI, HLI, and WS on the physiological and surrounding AT measurements taken, we considered changes from when water was turned off (spray duration period) and from when the coat was dry. The models used for this analysis (test $\mathrm{df}=1$, error $\mathrm{df}=14$ ) were similar to those described above except that we did not average values per cow and treatment and included cow and its interaction with the fixed term in the random effects. In addition, we used the ESTIMATE statement to obtain slopes that indicate the magnitude of the weather effects on the dependent variables.

In addition to weather, we evaluated the effects of baseline values (i.e., before the treatment was applied) on responses to heat load after the water was turned off using the same model described above (test $\mathrm{df}=1$, error $\mathrm{df}=14)$. All data were screened to confirm the normality and homoscedasticity of variances.

\section{RESULTS}

\section{Weather}

Weather information is described in Table 1. During the experimental period, rainfall was $0 \mathrm{~mm}$.

\section{Water Temperature}

Nozzle Outlet. Water temperature at the nozzle outlet averaged $29.7 \pm 1.4^{\circ} \mathrm{C}$ (mean $\pm \mathrm{SD}$; range: $24.0-38.8^{\circ} \mathrm{C}$; Figure 2 ) and was positively related to AT and THI (slope estimates $=0.53$ and 0.75 , respectively; $P<0.001$ ). When water was sprayed for $13 \mathrm{~min}$, the average temperature was lower than the other treatments (Figure $3, P<0.001$ ).

Water Dripping from the Cow. The temperature of the water dripping from the cows' side averaged 30.3 $\pm 0.8^{\circ} \mathrm{C}$ (mean $\pm \mathrm{SD}$; range: $26.5-36.0^{\circ} \mathrm{C}$; Figure 2). 
Table 1. Summary (averages of mean, minimum, and maximum) of weather conditions during $24 \mathrm{~h}$ and the experimental period (1115 to 1600 h)

\begin{tabular}{|c|c|c|c|c|c|c|}
\hline \multirow[b]{2}{*}{ Weather variable } & \multicolumn{3}{|c|}{$24 \mathrm{~h}$} & \multicolumn{3}{|c|}{ Experimental period } \\
\hline & Mean $\pm \mathrm{SD}$ & Minimum & Maximum & Mean $\pm \mathrm{SD}$ & Minimum & Maximum \\
\hline Air temperature $\left({ }^{\circ} \mathrm{C}\right)$ & $23.9 \pm 6.9$ & 13.7 & 40.6 & $31.2 \pm 3.3$ & 25.2 & 40 \\
\hline Relative humidity (\%) & $49 \pm 22$ & 9 & 84 & $27 \pm 10$ & 9 & 48 \\
\hline Black globe temperature $\left({ }^{\circ} \mathrm{C}\right)$ & $29.4 \pm 12.8$ & 12.6 & 54.9 & $45.8 \pm 3.1$ & 40.4 & 54.9 \\
\hline Solar radiation $\left(\mathrm{W} / \mathrm{m}^{2}\right)$ & $217 \pm 326$ & 0 & 879 & $785 \pm 69$ & 569 & 879 \\
\hline Wind speed $(\mathrm{m} / \mathrm{s})$ & $1.2 \pm 0.7$ & 0 & 3.5 & $1.5 \pm 0.5$ & 0.6 & 3.4 \\
\hline Heat load index & $69 \pm 19$ & 47 & 102 & $92 \pm 4$ & 79 & 102 \\
\hline Temperature-humidity index & $69 \pm 7$ & 57 & 76 & $76 \pm 2$ & 72 & 81 \\
\hline
\end{tabular}

Overall, spraying cows for 13 min resulted in warmer dripping water than in the other treatments $\geq 1.5 \mathrm{~min}$ (Figure $3, P \leq 0.018$ ). However, the dripping water temperature of the 13- and 0.5 -min treatments was similar $(P=0.418)$. Differences between dripping water and nozzle outlet temperatures averaged $0.3,-0.5,0.1$, and $2.6 \pm 0.3^{\circ} \mathrm{C}$ for the $0.5-, 1.5-, 3-$, and 13 -min treatments, respectively.

\section{Surrounding AT and Physiological Responses to Spray Duration}

$\boldsymbol{R} \boldsymbol{R}$. Sprayed water reduced RR only when it was applied for longer than $0.5 \mathrm{~min}$ in comparison with shade-only treatment. The magnitude of these changes was more pronounced when water was sprayed for longer $(P<0.001$, Figure 4a). Regardless of treatment, no further reduction in $\mathrm{RR}$ was observed after water was turned off (Figure 5a). Cows sprayed with water for $13 \mathrm{~min}$ had lower RR than all other treatments at all times cows were observed $(P<0.001$, Figure $5 \mathrm{a})$. When water was sprayed for either 1.5 or $3 \mathrm{~min}$, no differences in RR were observed during the 30-min period $(P \geq 0.280$, Figure 5a), and these 2 treatments reached similar RR to control cows 24 min after the water stopped $(P \geq 0.192$, Figure $5 \mathrm{a})$. The $\mathrm{RR}$ was similar when cows were sprayed for 0.5 or $1.5 \mathrm{~min}(P \geq$ 0.108 , Figure 5a). There were some exceptions: at min 6 and $15 \mathrm{RR}$ tended to be different $(P \leq 0.084)$, and 3 and 21 min after water was stopped there were differ-

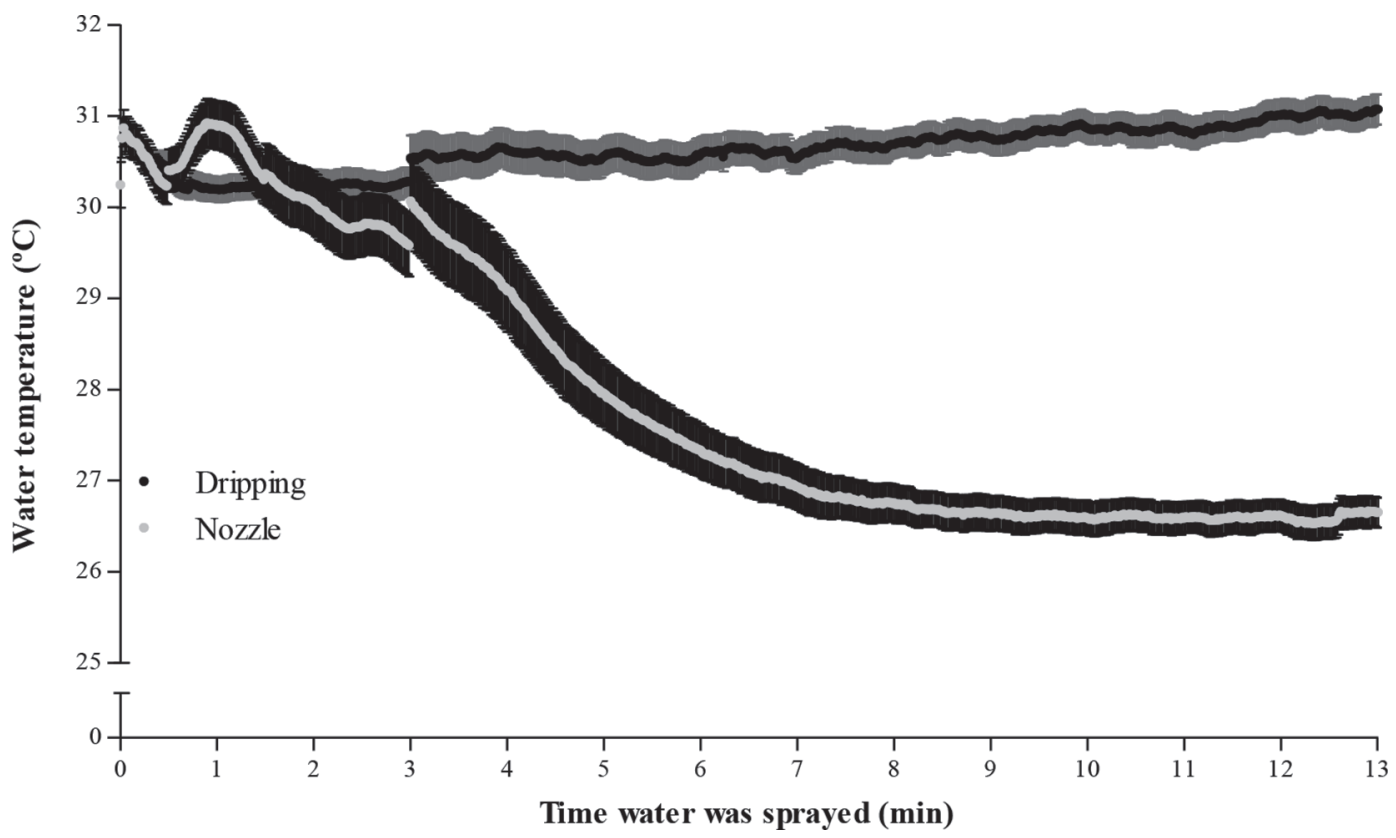

Figure 2. Mean $\pm \mathrm{SE}$ water temperature measured at the nozzle outlet and dripping from the cow as measured inside an adapted and insulated 30 -cm funnel over 13 min. Sample size is $\mathrm{n}=60$ for $\leq 0.5 \min , \mathrm{n}=45$ for $0.5<\mathrm{t} \leq 1.5 \min , \mathrm{n}=30$ for $1.5<\mathrm{t} \leq 3 \mathrm{~min}$, and $\mathrm{n}=15$ for $>3 \min (\mathrm{t}=$ time). 
ences in RR between these 2 treatments $(P \leq 0.020)$. Cows sprayed for 3 min maintained lower RR compared with 0.5 -min treatments during the 30 -min period cows were observed $(P \leq 0.049$, Figure 5a). There were also some exceptions: these treatments tended to be different $15 \mathrm{~min}$ after the water stopped $(P=0.087)$ and were similar at min 12, 24 and $30(P>0.160)$.

Skin Temperature. Immediately after 1 cycle of spray, the shoulder surface temperature decreased and this change was greatest for the 13 -min treatment $(P \leq$ 0.001 , Figure 4b). Once the water was turned off, skin temperature at this location increased over the 30-min period cows were monitored. However, when cows were sprayed, the shoulder temperature always remained lower than the control ( $P \leq 0.005$, Figure $5 b)$. Spraying cows for 13 min was more effective in reducing shoulder temperature than all other water treatments during the entire observation period $(P \leq 0.011$, Figure $5 \mathrm{~b})$. Reduction in shoulder temperature was similar when spraying cows for 1.5 or $0.5 \min (P \geq 0.113$, Figure $5 \mathrm{~b})$. There were some exceptions: $18 \mathrm{~min}$ after the spray stopped they tended to be different $(P=0.075)$, and at min 0 and 30 they were different from each other $(P$ $\leq 0.010)$. Overall, spraying cows for 3 min resulted in cooler shoulder temperatures than when spraying cows for $\leq 1.5 \min (P \leq 0.043$, Figure $5 \mathrm{~b})$. There were some exceptions to this general pattern. When comparing 0.5 - and 3-min treatments, they were not different at min 6 and $9(P>0.112)$. Also, when comparing 1.5 vs. 3 -min treatments, min 21 and 27 only tended to be

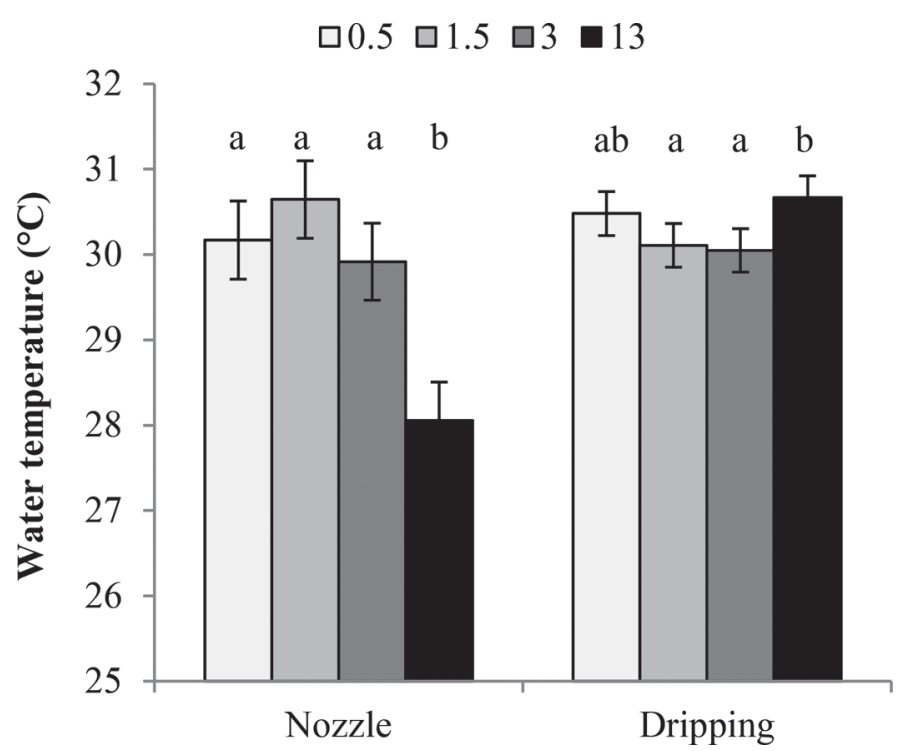

Figure 3. Least squares means $\pm \mathrm{SE}$ water temperature measured at the nozzle outlet and dripping from the cow as measured inside an adapted and insulated $30-\mathrm{cm}$ funnel by spray-duration treatment: 0.5 , $1.5,3$, or 13 min. Letters $(\mathrm{a}, \mathrm{b})$ indicate treatment differences $(P<$ $0.05)$. different $(P \leq 0.069)$ and min 3 to 9 and 30 had similar shoulder temperatures $(P>0.108)$.

Immediately after the spray was turned off, only treatments $\geq 3$ min reduced leg temperature relative to controls $(P<0.001$, Figure 4c). However, from min 3 and beyond, skin temperature at the leg was cooler for all water treatments tested $(P \leq 0.032$, Figure $5 \mathrm{c})$. There was one exception at $30 \mathrm{~min}$ after the water stopped, when shaded controls tended to be different than 1.5-min treatments or similar to 0.5 -min treatments $(P>0.062)$. Changes in leg temperature were more evident when cows were sprayed for $13 \mathrm{~min}$ compared with other water treatments $(P<0.001$, Figure $5 c)$. No differences in leg temperature were observed when spraying cows for $\leq 1.5 \mathrm{~min}(P \geq 0.432$, Figure $5 c)$. Spraying cows for 3 min resulted in lower leg temperatures than when applying water for $\leq 1.5 \mathrm{~min}(P \leq$ 0.044 , Figure 5c), except at min 9 when leg temperature only tended to be different among these treatments $(P$ $\leq 0.067)$, and min 18 when leg temperature was similar between 1.5 - and 3 -min treatments $(P=0.102)$.

Surrounding $\boldsymbol{A T}$. After a single spray application, the AT surrounding the leg tended to decrease as sprayed duration increased $(P \leq 0.056$, Figure $4 d)$. However, from 3 min after the spray stopped and beyond, the surrounding AT remained lower for all water treatments compared with shaded controls during the 30 min cows were observed $(P \leq 0.006$, Figure $5 \mathrm{~d})$. After water was turned off, the surrounding AT was not reduced further in any water treatment (Figure 5d). Overall, when cows were sprayed for $13 \mathrm{~min}$, the surrounding AT remained lower than in all other water treatments $(P \leq 0.044$, Figure $5 \mathrm{~d})$. There were a few specific exceptions, as surrounding AT converged to 3 -min treatment 27 min after the spray stopped ( $P$ $\geq 0.104)$ and tended to be different than the 1.5-min treatment at $\min 18(P=0.072)$. Spraying cows for 3 min resulted in lower surrounding AT compared with 1.5 min only up to 6 min after the spray stopped $(P \leq$ 0.012 , Figure $5 \mathrm{c}$ ). The surrounding AT was also cooler when spraying cows for 3 min compared with $0.5 \mathrm{~min}$ $(P \leq 0.048$, Figure 5c), except at min 18 and 24 when they were similar $(P \geq 0.139)$. Spraying cows for 1.5 min maintained the AT surrounding the cows lower than when cows were sprayed for $0.5 \mathrm{~min}$ up to $9 \mathrm{~min}$ after the water stopped and at min $15(P \leq 0.044$, Figure 5c). These 2 treatments were similar after min $21(P \geq 0.299)$; they tended to be different only 12 and 18 min after the spray stopped.

\section{Time for the Coat to Dry}

The coat became dry 14 to 16 min after the water stopped. Spray duration tended to affect time to dry: 
spraying cows for 13 min increased drying time by approximately $2 \min (15.9$ vs. $13.8,14.9$, and $14.2 \pm 0.6$ $\mathrm{min}$ for $0.5,1.5$, and $3 \mathrm{~min}$, respectively; $P \leq 0.070$ ).

\section{Baseline Values and Weather Effects}

Baseline values affected the magnitude of the changes caused by the spray water. Cows reduced their RR (Figure 6) and leg surface temperature more markedly when their baseline values were higher (slope estimates $=-0.53$ and -0.05 , respectively; $P \leq 0.030$ ).

Weather had little effect on the physiological measurements obtained immediately after water was turned off. On warmer days, RR tended to increase (slope estimate $=0.5, P=0.079)$, whereas shoulder temperature decreased (slope estimate $=-0.04, P=0.030$ ).

Time to dry was reduced in warmer (slope estimate $=$ $-0.2, P=0.004$ ) and windier (slope estimate $=-1.3$, $P=0.004$, Figure 7a) days. During drying, WS also affected the magnitude of change of some physiological measurements. Leg temperature decreased as WS increased (slope $=-0.06 ; P=0.019$, Figure $7 \mathrm{~b}$ ), whereas $\mathrm{RR}$ tended to be reduced during this the coat-drying period (slope $=-3.6 ; P=0.063$, Figure 7c). Weather only affected shoulder temperature after cows were dry on warmer days (slope $=0.05 ; P=0.002$ ).

\section{DISCUSSION}

In this study, cooling primarily was observed during the spray period, and, overall, relatively little cooling occurred during the drying phase that followed, contrary to what we hypothesized. Cooling benefits as well as changes in AT surrounding the leg were more pronounced when water was sprayed for longer. Dripping water temperature was stable over time and was usually warmer than the water temperature at the nozzle. Taken together, these results suggest that heat

\section{Spray duration (min): $\square 0 \square 0.5 \square 1.5 \square 3 \square 13$}

\section{a) Respiration rate}

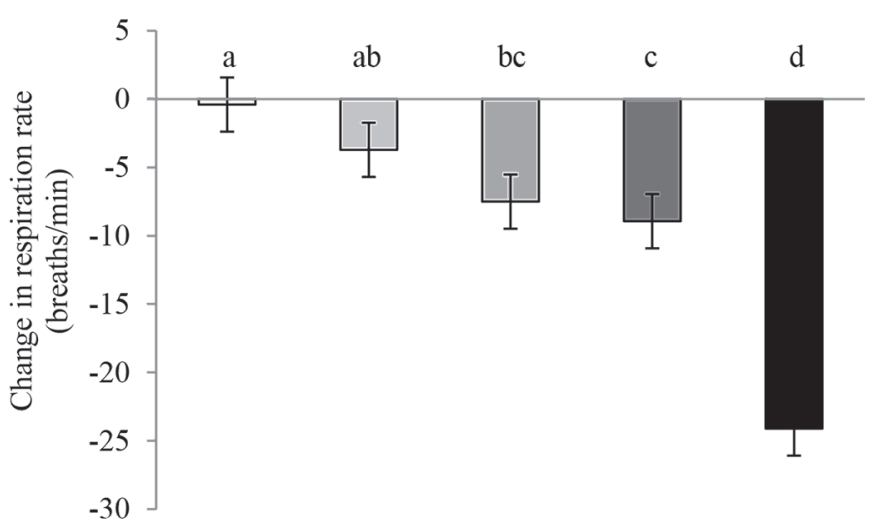

c) Leg temperature

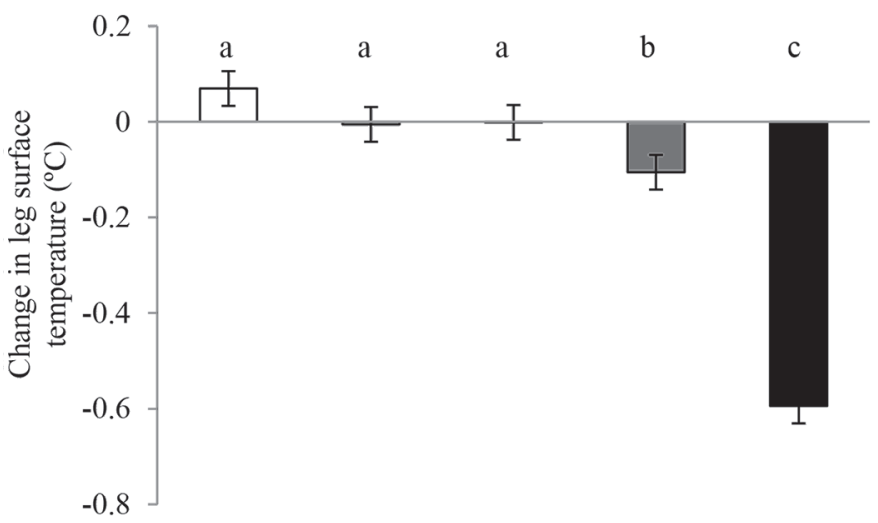

b) Shoulder temperature

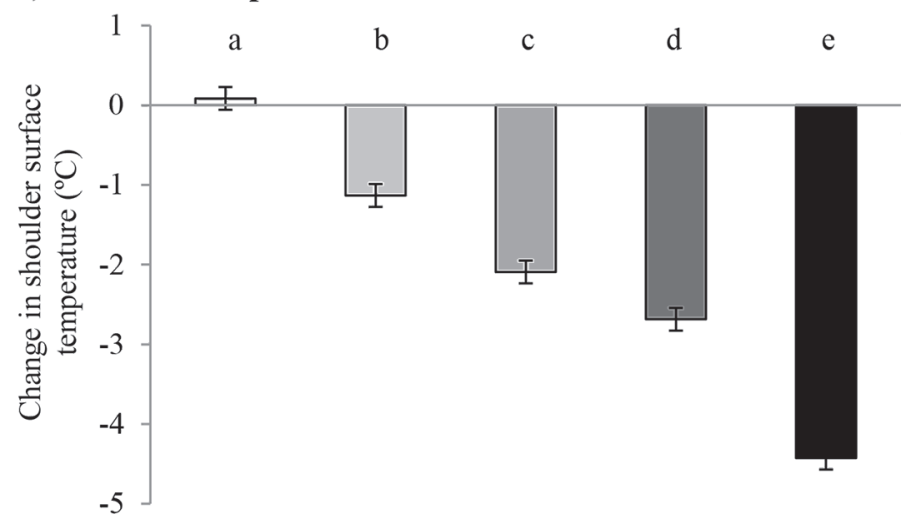

d) Surrounding air temperature

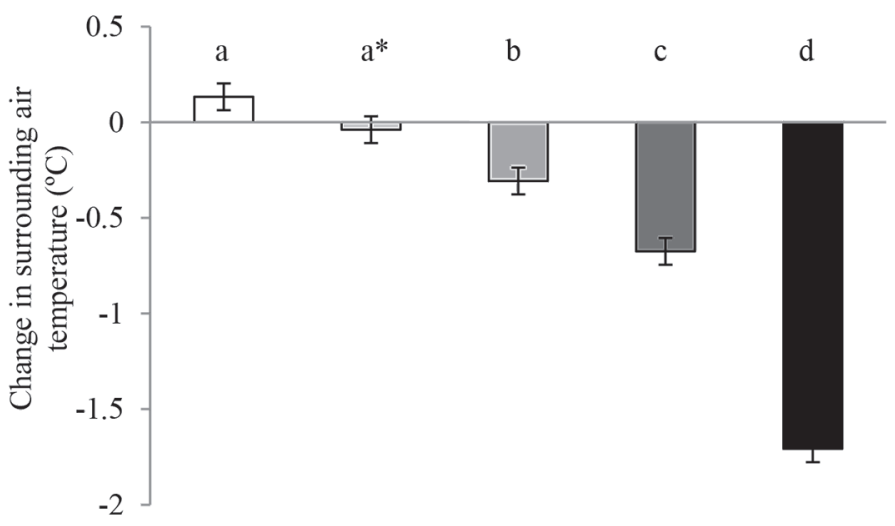

Figure 4. Least squares means $\pm \mathrm{SE}$ of change in (a) respiration rate, (b) skin temperature of the shoulder surface, (c) skin temperature of the leg surface, and (d) surrounding air temperature in response to a single spray $(0,0.5,1.5,3$, or 13 min) measured immediately after water was turned off $(\mathrm{n}=15$ cows). Letters $(\mathrm{a}-\mathrm{e})$ indicate treatment differences $(P<0.05)$; asterisk $(*)$ indicates a tendency $(P<0.09)$. 

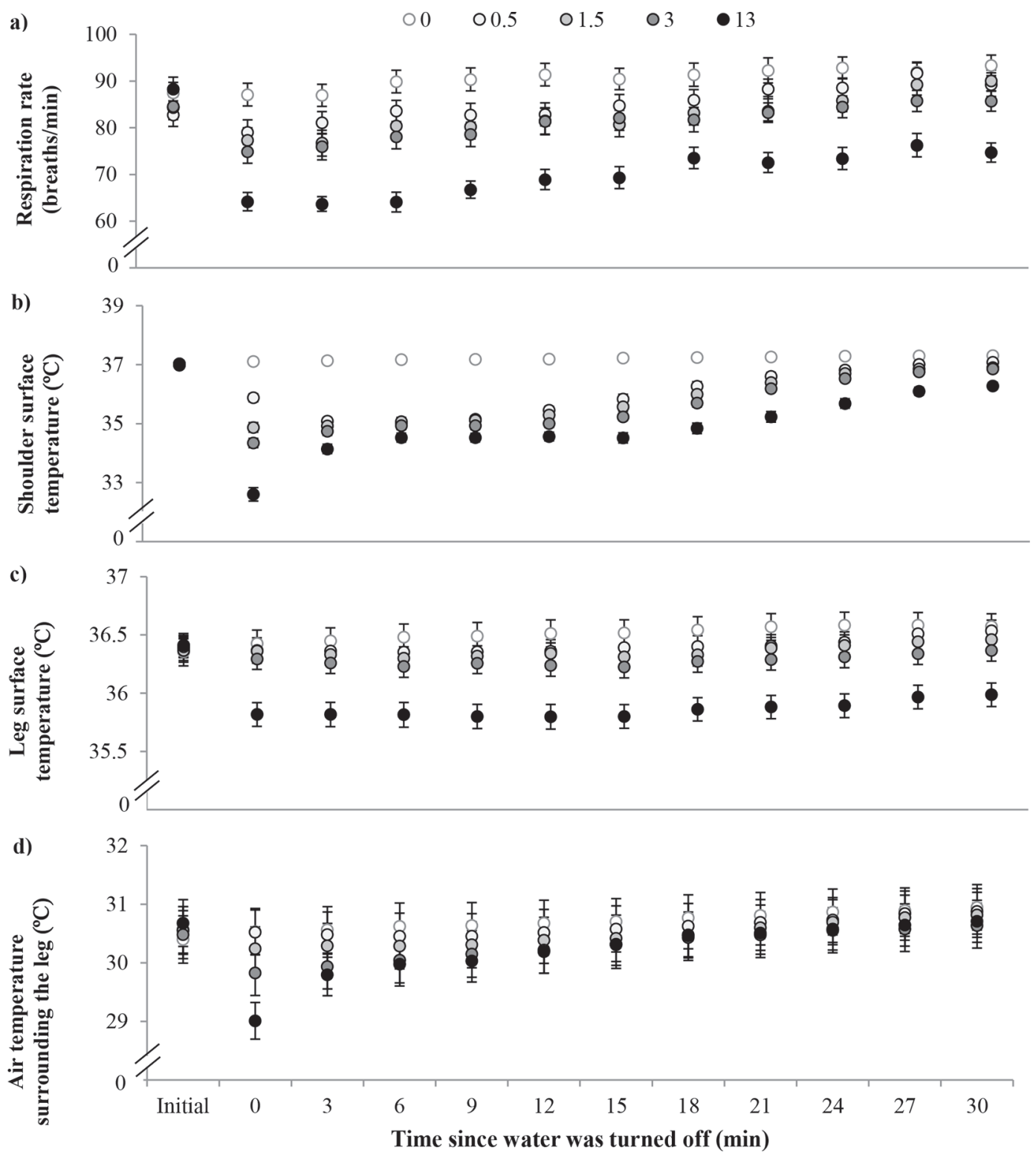

Figure 5. Least squares means $\pm \mathrm{SE}$ of (a) respiration rate, (b) skin temperature of the shoulder surface, (c) skin temperature of the leg surface, and (d) surrounding air temperature in response to a single spray $(0,0.5,1.5,3$, or 13 min). Measurements include values at baseline (initial) and up to 30 min after water was turned off $(\mathrm{n}=15$ cows).

was carried away from the body while water dripped off the cow. Responses during the spray phase were also affected by baseline values, with the magnitude of the changes being greater when cows were initially hotter. After the spray was turned off it took 14 to 16 min for the coat to become dry, and the spray duration had little biologically meaningful effect on this timing, as we hypothesized. In addition, no further cooling was recorded during the following $30 \mathrm{~min}$ that the cows were observed. However, on windier days, reductions in leg surface temperature and $\mathrm{RR}$ were greater during the coat-drying period.

\section{Effects of Spray Duration on Physiological Responses to Heat Load and Surrounding AT Immediately After the Water Was Turned Off}

The magnitude of the changes in RR, skin surface, and surrounding AT increased the longer the spray was on and, overall, was not affected by weather. Spraying cows for $13 \mathrm{~min}$ resulted in effective cooling and the lowest values for surrounding AT, RR, and skin temperature among the treatments tested. For example, when cows were exposed to 13 min of spray, their RR averaged 64 breaths/min, which compares with the low- 
est value we found on commercial dairies in CA during the summer (Tresoldi et al., 2017). The other treatments reduced RR by 4 to 9 breaths/min (average: 79 to 74 breaths/min), suggesting that the cooling benefits were minimal when water was sprayed for $\leq 3$ min once. It is likely that additional strategies to achieve cooling will be required (e.g., multiple spray applications; Chen et al., 2015). In our study, changes in RR and skin temperature were comparable with other studies only when values at the start of the treatment (i.e., baseline) were similar. For example, after 3 min of spray, changes in RR were similar to those found by Chen et al. (2015), and the baseline RR in that study averaged 88 breaths/min versus 87 breaths/min in our study. On the other hand, in this study, RR reduction was higher compared with what was found by Chen et al. (2016b) after spraying cows for $12 \mathrm{~min}$. This could be explained by differences in starting baseline values, as in their study initial RR averaged 20 breaths/min less than in the current work. We have demonstrated in this study that baseline values affected the outcomes obtained after spraying cows with water: the magnitude of the changes was higher when cows were warmer at the start (indicated by higher RR and leg temperature). This result indicates that baseline values should be considered when comparing similar treatments across studies.

The lack of weather effects in most of the variables measured could be due to the design of our testing

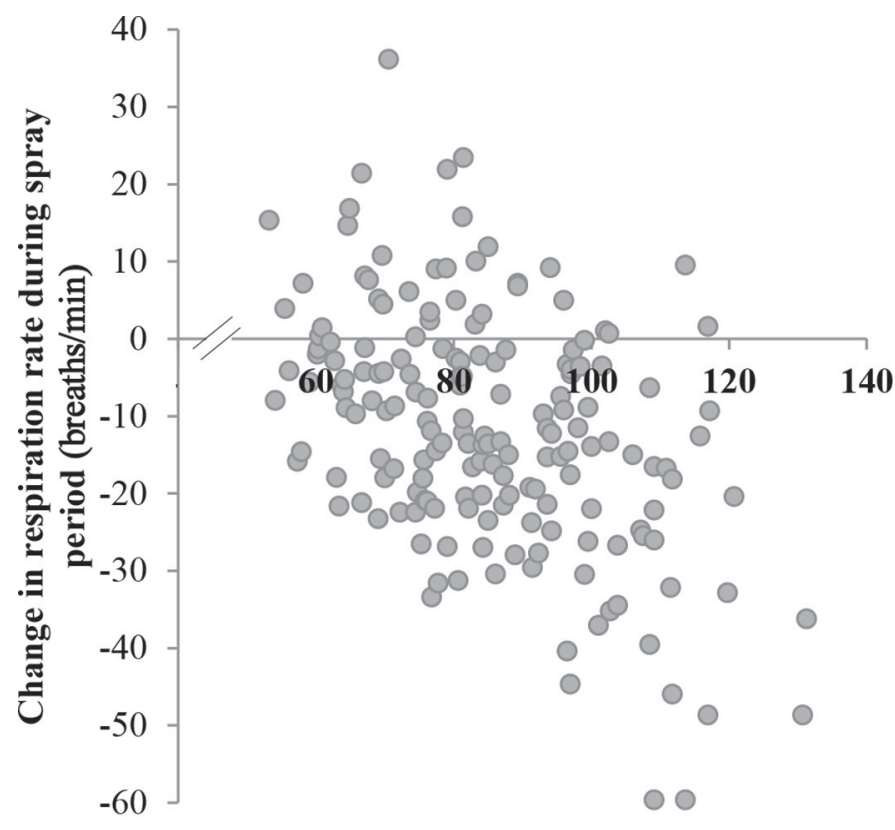

Baseline respiration rate values (breaths/min)

Figure 6. Relationship between changes in respiration rate and baseline values ( $\mathrm{n}=15$ cows, measured $15 \mathrm{~d}$ in total).
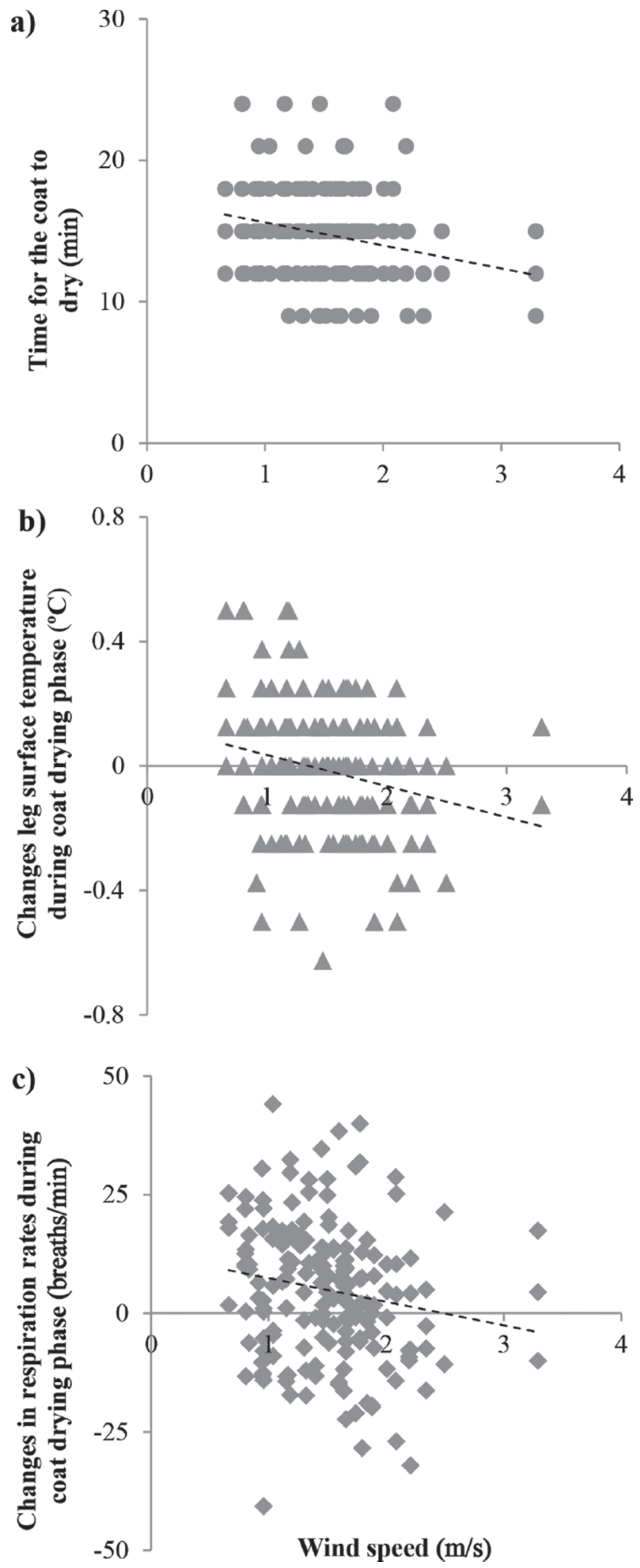

Figure 7. Relationship between wind speed and (a) the time it took for the coat to dry, (b) changes in leg surface temperature, and (c) respiration rate during this period. Dashed lines indicate the line of best fit ( $\mathrm{n}=15$ cows, measured $12 \mathrm{~d}$ in total). 
pens. In this experiment, cows were protected from direct sunlight (as they were tested in shaded pens), and plywood sheets divided the pens to minimize water drift. When studying the effects of sprayed water in unshaded cattle, Chen et al. (2015) found that all physiological measures were significantly affected by weather. However, the entrance and head gates of the pens were open, permitting the air to flow, allowing for WS effects.

In our study, other aspects beyond water application may have contributed to the cooling effectiveness of the longest treatment. For example, the AT surrounding the cows was lowest for the 13-min treatment compared with the other treatments for up to 27 min after the water was turned off. Other studies have shown through mathematical models that cooler microclimates could enhance heat losses (McArthur, 1987; Gebremedhin and $\mathrm{Wu}, 2002)$, whereas others hypothesized that sprayed water could chill the air cows inhale (Bucklin et al., 1991), leading to more cooling. In addition, spraying water for $13 \mathrm{~min}$ resulted in the lowest water temperature at the nozzle; overall, it was at least $1.8^{\circ} \mathrm{C}$ cooler than treatments $\leq 3 \mathrm{~min}$. Although the effects of the temperature of the water sprayed on responses to heat load and behavior in cattle are still unknown, others have found that chilled drinking water reduces $\mathrm{RR}$ and body temperature in cattle, likely because of its heat-absorbing capacity (Stermer et al., 1986; Wilks et al., 1990; Bewley et al., 2008). In addition, cooler sprayed water may remove more heat from the body. In our study, the magnitude of the difference between the sprayed and dripping water temperature was highest for 13-min treatment, suggesting that this treatment had the greatest capacity to remove heat from the skin when water was being directly sprayed. Although our water temperature results seem to indicate that cows exposed to 1.5-min treatment are gaining heat (spray onto the cow $>$ dripping off of the cow), this result does not match the results obtained from physiological measures. This discrepancy could be due to differences in water temperature between the nozzle outlet and hitting the cows. Sprayed water temperature decreases as distance from the water outlet increases (Hsieh et al., 2015); thus, the temperature of the water that contacts the cows should be lower than what we measured at the nozzle. In a pilot test we conducted, we found that the temperature of the water at cow height (measured using the same method as dripping water temperature) was on average $( \pm \mathrm{SD}) 2.0 \pm 0.1^{\circ} \mathrm{C}$ lower than at the nozzle (data not shown).

Contrarily to our hypothesis that spray duration would have a linear effect on physiological responses to heat load and surrounding AT, our results were incon- sistent when testing treatments $\leq 3 \mathrm{~min}$. For example, $\mathrm{RR}$ was only reduced when spraying cows for $>1.5$ min. However, the 1.5-min treatment was not different compared with spraying cows for 0.5 or $3 \mathrm{~min}$, although we could expect more marked differences among these treatments due to changes in the surrounding AT and heat-absorbing capacity of the water. When the water is sprayed for longer, there are likely more opportunities for the heat to be transferred from the cows' body to the dripping water compared with shorter spray duration. In addition, in these short-duration treatments, the cooling responses varied within the same treatment depending on the variable measured. For example, spraying cows for 1.5 min reduced the surrounding AT and shoulder temperature but not leg temperature in relation to shaded controls. Additional information is needed to understand how multiple cumulative shortspray duration affects physiological responses to heat load in cattle.

\section{Effects of Duration of Spray on Time to Dry and on the Physiological Responses to Heat Load and Surrounding AT After Spray Ends}

Duration of spray tended to affect time for the coat to become dry in this study, but the biological relevance of such differences is unclear. The coat took 14 to 16 min to dry, which is similar to drying times anecdotally described by Perano et al. (2015) when spraying cows for $1 \mathrm{~min}$ (flow rate of $0.8 \mathrm{~kg} / \mathrm{min}$ with fans; no WS was reported) but is almost 3-fold higher than that reported by Flamenbaum et al. (1986) when using forced ventilation ( 4 fans, WS $=1.5-3 \mathrm{~m} / \mathrm{s}$ ). In our study, time to dry was reduced on warmer and windier days, which was comparable with evaporation rates (by sweat) described in cattle (Gebremedhin et al., 2008).

Cows sprayed for $13 \mathrm{~min}$ had the lowest RR and skin temperatures after the spray was turned off, and these usually remained lower than all other treatments during the following $30 \mathrm{~min}$ they were observed. Over time, all measures evaluated increased after water was turned off independently of treatment, indicating that cows were cooled only when they received the direct spray. A similar pattern was reported by Flamenbaum et al. (1986). In their study, cows became warmer when they were moved to another area without any cooling resources. However, on windier days, changes in RR and leg surface temperature were more pronounced during the drying period (i.e., more cooling was observed in this phase). These results suggest that cooling benefits can be enhanced when air flow is increased and applied directly to the cows while their coat is drying, as reported in other studies (Brouk et al., 2003). 


\section{CONCLUSIONS}

Cooling benefits, as well as changes in AT surrounding the leg, were more pronounced when water was sprayed for a longer period of time. In this study, the magnitude of these changes could be attributed to baseline values, sprayed water temperature, surrounding microclimate (i.e., AT around the cow, which was affected by the spray), and heat-exchange mechanisms that occur when water was being sprayed and dripping from the cows. Coats took between 14 and 16 min to dry, and no additional cooling was observed in this drying period except on windier days, indicating that cows can benefit from additional air flow when being sprayed.

\section{ACKNOWLEDGMENTS}

We are grateful to those who assisted with data collection: Pauline Lima (supported by the Science Without Borders Program, Brasilia, Brazil), Emma Williams, Adolfo Porras, Bradley Whelchel, Tony Phan, Amanda Crofton, Che Wei Hsu, Jason Tong, Jessica Schlarbaum, Karen Sin, Kassandra Mejia, and Veronica Wang [all affiliated with the University of California (UC), Davis at the time of the study]. We also thank Doug Gisi, Maria Patino, and the staff and interns of the UC Davis Dairy and Teaching Facility; Daniel Sehnert, Frank Sauers, Jose Villasenor, Floriana Petrone, and Parsa Taheri (all affiliated with UC Davis at the time of the study); and Fernando Dantas (University of Manchester, UK). We also thank Joy Mench and the reviewers for their comments in this manuscript. We gratefully acknowledge the financial support of Coordenação de Aperfeiçoamento de Pessoal de Nível Superior (CAPES) Foundation (Brasilia, Brazil; process BEX 0764/12-4, awarded to G. Tresoldi), Jastro Shields Award (Davis, CA), USDA multi-state research project W2173 and W3173 (Washington, DC), and the infrastructure support of the Department of Animal Science and the College of Agricultural and Environmental Sciences of the University of California, Davis.

\section{REFERENCES}

Anderson, S. D., B. J. Bradford, J. P. Harner, C. B. Tucker, C. Y. Choi, J. D. Allen, L. W. Hall, S. Rungruang, R. J. Collier, and J. F. Smith. 2013. Effects of adjustable and stationary fans with misters on core body temperature and lying behavior of lactating dairy cows in a semiarid climate. J. Dairy Sci. 96:4738-4750. https://doi.org/10.3168/jds.2012-6401.

Bewley, J. M., M. W. Grott, M. E. Einstein, and M. M. Schutz. 2008. Impact of intake water temperatures on reticular temperatures of lactating dairy cows. J. Dairy Sci. 91:3880-3887. https://doi.org/ $10.3168 /$ jds.2008-1159.
Brouk, M. J., J. F. Smith, and J. P. Harner III. 2003. Effect of sprinkling frequency and airflow on respiration rate, body surface temperature and body temperature of heat stressed dairy cattle. Pages 263-268 in Proc. 5th International Dairy Housing, Fort Worth, TX. ASAE, St. Joseph, MI.

Bucklin, R. A., L. W. Turner, D. K. Beede, D. R. Bray, and R. W Hemken. 1991. Methods to relieve heat stress for dairy cows in hot, humid climates. Appl. Eng. Agric. 7:241-247. https://doi.org/10 .13031/2013.26218.

Chen, J. M., K. E. Schütz, and C. B. Tucker. 2013. Dairy cows use and prefer feed bunks fitted with sprinklers. J. Dairy Sci. 96:50355045. https://doi.org/10.3168/jds.2012-6282.

Chen, J. M., K. E. Schütz, and C. B. Tucker. 2015. Cooling cows efficiently with sprinklers: Physiological responses to water spray. J. Dairy Sci. 98:6925-6938. https://doi.org/10.3168/jds.2015-9434.

Chen, J. M., K. E. Schütz, and C. B. Tucker. 2016a. Cooling cows efficiently with water spray: Behavioral, physiological, and production responses to sprinklers at the feed bunk. J. Dairy Sci. 99:4607-4618. https://doi.org/10.3168/jds.2015-10714.

Chen, J. M. K. E. Schütz, and C. B. Tucker. 2016b. Sprinkler flow rate affects dairy cattle avoidance of spray to the head, but not overall, in an aversion race. Appl. Anim. Behav. Sci. 179:23-31. https://doi.org/10.1016/j.applanim.2016.03.007.

Flamenbaum, I., D. Wolfenson, M. Mamen, and A. Berman. 1986 Cooling dairy cattle by a combination of sprinkling and forced ventilation and its implementation in the shelter system. J. Dairy Sci. 69:3140-3147. https://doi.org/10.3168/jds.S0022-0302(86)80778 -0 .

Gaughan, J. B., T. L. Mader, S. M. Holt, and A. Lisle. 2008. A new heat load index for feedlot cattle. J. Anim. Sci. 86:226-234. https://doi.org/10.2527/jas.2007-0305.

Gebremedhin, K. G., P. E. Hillman, C. N. Lee, R. J. Collier, S. Willard, J. D. Arthington, and T. M. Brown-Brandl. 2008. Sweating rates of dairy cows and beef heifers in hot conditions. Trans. ASABE 51:2167-2178. https://doi.org/10.13031/2013.25397.

Gebremedhin, K. G., and B. Wu. 2002. Simulation of sensible and latent heat losses from wet-skin surface and fur layer. J. Therm. Biol. 27:291-297. https://doi.org/10.1016/S0306-4565(01)00091-2.

Hillmann, P. E., K. G. Gebremedhin, A. Parkhurst, J. Fuquay, and S. Willard. 2001. Evaporative and convective cooling of cows in a hot and humid environment. Pages 343-350 in Proc. 6th International Symposium of Livestock Environment, Louisville, KY. ASAE, St. Joseph, MI.

Hsieh, S. S., G. W. Chen, and Y. F. Yeh. 2015. Optical flow and thermal measurements for spray cooling. Int. J. Heat Mass Transfer 87:248-253. https://doi.org/10.1016/j.ijheatmasstransfer.2015.04 .005 .

Kelly, C. F., and T. E. Bond. 1971. Bioclimatic factors and their measurement. Page 7-92 in A Guide to Environmental Research on Animals. National Research Council, ed. National Academies Press, Washington, DC.

Kendall, P. E., G. A. Verkerk, J. R. Webster, and C. B. Tucker. 2007. Sprinklers and shade cool cows and reduce insect-avoidance behavior in pasture-based dairy systems. J. Dairy Sci. 90:3671-3680. https://doi.org/10.3168/jds.2006-766.

Kimmel, E., H. Arkin, D. Broday, and A. Berman. 1991. A model of evaporative cooling in a wetted hide. J. Agric. Eng. Res. 49:227241. https://doi.org/10.1016/0021-8634(91)80041-C.

McArthur, A. J. 1987. Thermal interaction between animal and microclimate: A comprehensive model. J. Theor. Biol. 126:203-238. https://doi.org/10.1016/S0022-5193(87)80229-1.

Means, S. L., R. A. Bucklin, R. A. Nordstedt, D. K. Beede, D. R. Bray, C. J. Wilcox, and W. K. Sanchez. 1992. Water application rates for sprinklers and fan dairy cooling system in hot, humid climates. Trans. ASAE 8:374-378. https://doi.org/10.13031/2013.26080.

Morrison, S. R., M. Prokop, and G. P. Lofgreen. 1981. Sprinkling cattle for heat stress relief: Activation temperature, duration of sprinkling and pen area sprinkled. Trans. ASAE 24:1299-1300. https://doi.org/10.13031/2013.34438.

Perano, K. M., J. G. Usack, L. T. Angenent, and K. G. Gebremedhin. 2015. Production and physiological responses of heat-stressed 
lactating dairy cattle to conductive cooling. J. Dairy Sci. 98:52525261. https://doi.org/10.3168/jds.2014-8784.

SAS Institute. 2009. SAS/STAT 9.2 User's Guide. Vol. 2. SAS Institute Inc., Cary, NC.

Stermer, R. A., C. F. Brasington, C. E. Coppock, J. K. Lanham, and K. Z. Milam. 1986. Effect of drinking water temperature on heat stress of dairy cows. J. Dairy Sci. 69:546-551. https://doi.org/10 .3168/jds.S0022-0302(86)80436-2.

Tresoldi, G., K. E. Schütz, and C. B. Tucker. 2017. Cow cooling on commercial drylot dairies: A description of 10 farms in California. Calif. Agric. 71:249-255. https://doi.org/10.3733/ca.2017a0042.

Valtorta, S. E., and M. R. Gallardo. 2004. Evaporative cooling for Holstein dairy cows under grazing conditions. Int. J. Biometeorol. 48:213-217. https://doi.org/10.1007/s00484-003-0196-9.
Wilks, D. L., C. E. Coppock, J. K. Lanham, K. N. Brooks, C. C. Baker, and W. L. Bryson. 1990. Responses of lactating Holstein cows to chilled drinking water in high ambient temperatures. J. Dairy Sci. 73:1091-1099. https://doi.org/10.3168/jds.S0022 -0302(90)78768-1.

World Resources Institute. 2011. World Resources 2010-2011: Decision Making in a Changing Climate-Adaptation Challenges and Choices. World Resources Institute, United Nations Development Program, United Nations Environment Program, Washington, DC 